\title{
Diagnosis of myocardial infarction at autopsy: AECVP reappraisal in the light of the current clinical classification
}

\author{
Katarzyna Michaud ${ }^{1}$ (D) $\cdot$ Cristina Basso $^{2} \cdot$ Giulia d'Amati $^{3} \cdot$ Carla Giordano $^{3} \cdot$ Ivana Kholová $^{4}$ (D) Stephen D. Preston ${ }^{5}$. \\ Stefania Rizzo ${ }^{2}$. Sara Sabatasso ${ }^{6} \cdot$ Mary N. Sheppard $^{7}$ - Aryan Vink ${ }^{8}$. Allard C. van der Wal ${ }^{9}$ (D - on behalf of the \\ Association for European Cardiovascular Pathology (AECVP)
}

Received: 13 June 2019 / Revised: 21 August 2019 / Accepted: 28 August 2019/Published online: 14 September 2019

(C) The Author(s) 2019

\begin{abstract}
Ischemic heart disease is one of the leading causes of morbidity and death worldwide. Consequently, myocardial infarctions are often encountered in clinical and forensic autopsies, and diagnosis can be challenging, especially in the absence of an acute coronary occlusion. Precise histopathological identification and timing of myocardial infarction in humans often remains uncertain while it can be of crucial importance, especially in a forensic setting when third person involvement or medical responsibilities are in question. A proper post-mortem diagnosis requires not only up-to-date knowledge of the ischemic coronary and myocardial pathology, but also a correct interpretation of such findings in relation to the clinical scenario of the deceased. For these reasons, it is important for pathologists to be familiar with the different clinically defined types of myocardial infarction and to discriminate myocardial infarction from other forms of myocardial injury. This article reviews present knowledge and postmortem diagnostic methods, including post-mortem imaging, to reveal the different types of myocardial injury and the clinicalpathological correlations with currently defined types of myocardial infarction.
\end{abstract}

Keywords Myocardial infarction · Myocardial injury · Autopsy · Acute coronary syndromes · Post-mortem imaging · Immunohistochemistry

\section{Introduction}

Acute ischemic heart syndromes, which are acute myocardial infarction (MI), various types of unstable angina and sudden coronary death, are the prevailing acute life-threatening diseases with high mortality rates. They occur not only in the Western World but also in industrialized developing countries

Katarzyna Michaud

katarzyna.michaud@chuv.ch

Allard C. van der Wal

a.c.vanderwal@amc.uva.nl

1 University Center of Legal Medicine Lausanne - Geneva, Lausanne University Hospital and University of Lausanne, Chemin de la Vulliette 4, CH - 1000 Lausanne 25, Switzerland

2 Cardiovascular Pathology, Department of Cardiac, Thoracic, Vascular Sciences and Public Health, University of Padua, Padua, Italy

3 Department of Radiological, Oncological and Pathological Sciences, Sapienza, University of Rome, Rome, Italy
$[1,2]$. Consequently, a diagnosis of MI or sudden coronary death is often considered in situations of clinical or forensic autopsy. Coronary artery disease (CAD), which underlies most cases of MI, and also the ischemic myocardial pathology in different stages of injury and repair have been studied extensively to improve post-mortem diagnosis. Ancillary techniques to visualize ischemic injury have been developed or are now

4 Pathology, Fimlab Laboratories and Faculty of Medicine and Health Technology, Tampere University, Tampere, Finland

5 Royal Papworth Hospital, Papworth Everard, Cambridge CB23 3RE, UK

6 University Center of Legal Medicine Lausanne-Geneva, Geneva University Hospital and University of Geneva, Geneva, Switzerland

7 Department of Cardiovascular Pathology, Cardiology Clinical Academic Group, Molecular and Clinical Sciences Research Institute, St George's Medical School, London, UK

8 University Medical Center Utrecht, Utrecht University, Utrecht, The Netherlands

9 Amsterdam UMC, Academic Medical Center, Meibergdreef 9, 1105AZ Amsterdam, The Netherlands 
under investigation for improvement [3-5]. Recent developments are non- (or minimally invasive) post-mortem imaging techniques to detect coronary occlusion and ischemic injury in order to serve as an adjunct to, or even to replace, cardiac autopsy with presumed ischemic death [6,7]. These novel post-mortem approaches presently attract much interest; autopsy rates tend to decrease gradually in many countries [8].

However, in some situations, these diagnostic modalities alone may prove inadequate or insufficient to explain a clinical suspicion of myocardial ischemia. Examples are the sudden coronary deaths without thrombus, the cases of peri-procedural myocardial ischemia after therapeutic coronary interventions (in which early myocardial ischemia cannot be detected yet) or the non-coronary causes of ischemia. Finally, in some cases, also types of myocardial injury other than ischemic should be considered. This is reflected in the current clinical classification of MI, which discriminates five types with differences in etiological background, pathogenic mechanisms and evolving treatment strategies [9].

In this article, we review the present knowledge and post-mortem diagnostic methods to reveal MI at autopsy, how it should be discriminated from other forms of myocardial injury, and in particular, how pathology should be interpreted in relation to currently defined clinical types of MI.

\section{Clinical diagnosis of $\mathrm{MI}$}

Clinical diagnosis of MI is based on the presence of elevated cardiac troponin levels, in combination with prolonged chest pain, ECG recordings or regional wall motion abnormalities indicative of recent onset ischemia or angiographic detection of a coronary thrombus. Based on huge variety in the pathophysiology underlying MI, a subdivision into five distinct subtypes has recently been updated in the 4th universal definition of myocardial infarction document (2018) published by the Joint Task Force of the European Society of Cardiology, the American College of Cardiology Foundation, the American Heart Association and the World Heart Federation [9] (Table 1).
Type $1 \mathrm{MI}$ is the result of acute coronary artery atherothrombosis. In clinical series, based on in vivo imaging studies, thrombotic coronary events can be observed in about $80 \%$ of patients with acute coronary syndromes (ACS), although percentages may vary due to different diagnostic modalities and differences in demographic features of the patient groups involved. For therapeutic reasons, it is important to further classify the type 1 infarctions based on ECG findings as either ST elevation types of MI (STEMI) or non-ST elevation types of MI (nonSTEMI).

Type $2 \mathrm{MI}$ are infarctions that result from myocardial oxygen supply-demand imbalance and are not due to acute coronary plaque disruption and thrombosis. For example, MI with angiographically normal or low-grade stenosis (stenosis $\leq 50 \%$ ) is a clinically well-recognized syndrome (called MI with non-obstructive coronary arteries, MINOCA), caused by a variety of pathology in and outside the heart. MI type 2 includes also relatively rare nonatherosclerotic coronary diseases such as spontaneous dissection or embolization. Nevertheless, it should be noted that stable (not thrombosed) coronary plaques are commonly present in patients with type 2 MI. Diseases that may cause or at least contribute to oxygen supply-demand mismatch leading to myocardial injury are listed in Table 2. Altogether, reported frequencies of type $2 \mathrm{MI}$ vary from 10 to $30 \%$ of all MI patients.

Patients who present with clinical symptoms that are highly suspicious of MI in combination with new ECG changes or are in ventricular fibrillation (VF), but who die before cardiac biomarkers of ischemia can be identified, are designated as type 3 MI. They have reported frequency of 3-4\% of all MI [10].

MI diagnosed by a significant rise of biomarkers related to percutaneous coronary revascularization procedures are designated as type 4 MI. They can be temporally related to the procedure (within $48 \mathrm{~h}$ ) leading to critical myocardial flow reduction, but may also be due to acute complications of a device such as instent thrombosis, coronary dissection or the late stent complications such as restenosis and late onset thrombosis.

Similarly, type $5 \mathrm{MI}$ is due to ischemic injury associated with coronary artery bypass grafting (CABG) within $48 \mathrm{~h}$ of the procedure. It can be procedure-related, or related to low-flow, poor run-off or reperfusion damage.

Table 1 ESC/AHA/ACC/WHF classification of MI 2018 [9]

Type 1 Acute atherothrombotic occlusion or mural thrombus with critical flow reduction initiated by plaque rupture or erosion

Type 2 Ischemic injury due to a myocardial oxygen supply-demand mismatch, which is not caused by coronary atherothrombosis (Table 2)

Type 3 Cardiac death in a clinical setting suggestive of ischemic injury (chest pain, ECG changes) but without definitive cardiac biomarker evidence

Type 4 PCI-related ischemic injury $<48 \mathrm{~h}$ after procedure. Includes also cases of MI due to late stent thrombosis or restenosis

Type 5 CABG-related ischemic injury $<48 \mathrm{~h}$ after the procedure

ESC, European Society of Cardiology; AHA, American Heart Association; ACC, American college of Cardiology; WHF, World Heart Federation 
Table 2 Causes of MI without atherothrombotic coronary artery disease

Fixed coronary atherosclerotic plaques

Non-atherosclerotic coronary artery disease

Non-coronary cardiac oxygen demand-supply imbalance

Extra cardiac oxygen demand-supply imbalance
In combination with non-coronary causes of oxygen

demand-supply imbalance

Spasm/SVD, vasculitis, dissection, embolism, congenital anomalies, fibromuscular dysplasia, iatrogenic (stent or graft restenosis), PCI-related no-reflow

Sustained tachyarrhythmias, bradyarrhythmias,

LV hypertrophy and/or dilatation

Respiratory failure, severe anaemia, hypovolemic shock

\section{Ischemia and other forms of myocardial injury}

In clinical guidelines, a distinction is made between myocardial injury, which encompasses any form of acute myocardial damage or destruction, and MI, resulting from myocardial ischemia only [9]. Evidently, MI is a form of myocardial injury, and both entities share the presence of raised serum levels of cardiac troponin (cTn) in a patient. In order to discriminate clinically a MI from other types of myocardial injury, additional criteria such as angina symptoms and characteristic ECG changes are needed. Most important other forms of myocardial injury are listed in Table 3 and should be considered by pathologists at autopsy in the differential diagnosis of MI. For example, differential diagnosis of myocarditis is not always presented by clinical settings and this differentiation may arise from pathological standpoint [11].

\section{Anatomical substrates of myocardial infarction at autopsy}

\section{Coronary artery pathology}

\section{Acute obstruction and critical stenosis}

The most frequent cause of acute myocardial ischemia is atherothrombotic occlusion of a coronary artery $[3,12]$. The presence of a mural or totally occlusive thrombotic mass can be observed at autopsy in approximately $50-70 \%$ of sudden coronary deaths and is a reliable marker of myocardial ischemia, even in absence of microscopically visible necrosis $[12,13]$. This implies that in cases of sudden death, acute coronary occlusion can explain arrhythmic death [3].

The underlying pathology of mural or occlusive coronary thrombosis is variable and can be due to plaque ruptures, erosions or, less frequently, protruding calcified nodules. Also, intraplaque haemorrhages contribute to the acute flow reduction in these instances [14-16]. It is important to note that there can be a considerable time interval between the onset of plaque disruption and the evolving critical stenosis or occlusion by thrombus. And also the onset of necrosis in the heart and the clinical manifestation of symptoms of MI are not always around the same time $[17,18]$. It is not rare to find even organized thrombi or significant myocardial necrosis at autopsy in a patient with acute onset of ischemic symptoms $[18,19]$.

At autopsy, the main coronary arteries and large branches such as diagonal and obtuse marginal are examined by transversely sectioning at 3-mm intervals to identify thrombus and critical stenosis. For reliable interpretation, heavily calcified arteries are decalcified prior to cross sectioning. The most severely affected sections can be sampled for histology [3]

\section{Stenosis due to stable (not thrombosed) plaques}

The first assessment of luminal stenosis made by the eye is moderately consistent and accurate measure at low $(<30$
Table 3 Most frequent causes of myocardial injury, other than myocardial ischemia

\author{
Myocarditis \\ Cardiomyopathies \\ Radiation-induced injury \\ Drugs \\ Endogenous catecholamines \\ Cardiac interventions \\ Trauma \\ Sepsis \\ Cerebrovascular accidents \\ Chronic kidney disease \\ After cardiac transplantation
}

Toxic, immune mediated, infectious
Adrenergic, RAAS, cytokine and mechanical stress
Various mechanisms of myocardial cell death
May cause ischemic injury or other types of injury
Takotsubo, stress, extreme exercise
Cardiac surgery, PCI, TAVI, ablation procedures
Cardiac contusion, CPR-related tissue damage
Extreme cytokine release
Catecholamines and (neuro)inflammatory response
Mechanical stress, toxic uraemic
Myocardial immune injury (cellular and humoral rejection) 
$50 \%)$ and high (>70-75\%) grade stenosis. Accuracy can be improved by a visual aid, similar to that in Fig. 1 [20]. Ideally, gross assessments should be confirmed by histology, taking the internal elastic lamina as the original lumen size. This approach has a good inter-observer reproducibility in highdegree lesions [21]. However, lumen shape may affect the interpretation of stenosis, with pathologists overestimating the stenosis caused by slit-like lumens, and underestimating concentric and eccentric stenosis [22]. Geometric remodelling of the artery contributes importantly to the rate of lumen stenosis. Arteries are dynamic organs, in which compensatory expansive enlargement in association with unstable plaques and constrictive shrinkage in stable collagen-rich plaques is known as positive and negative remodelling respectively [23]. In case of a fixed stenotic stable plaque of $>75 \%$ stenosis, concomitant functional alterations such as exercise or spasm can evoke irreversible myocardial injury. Therefore, a stenosis of $75 \%$ or more is considered as critical $[24,25]$. Stenosis of $90 \%$ or more leaves myocardium ischemic even at rest and can be seen as a 'pinpoint' lumen less than $1 \mathrm{~mm}$ in diameter. Many of these stenoses have stable tissue composition of fibrous tissue and calcifications but without thrombus [25]. In these instances, microscopy of malperfused territories of the myocardium can be a helpful adjunct in diagnosis. Clinically, these infarctions are diagnosed as type 2 MI. However, in some cases, mural thrombus can be identified histologically, which implies a reclassification to type $1 \mathrm{MI}$. The evidence described so far relates to atherosclerotic CAD. Other conditions that may cause coronary stenosis are listed in the differential diagnosis of type 2 MI (Table 2).

\section{Coronary spasm}

Coronary artery spasm (CAS) is defined as an intense constriction of the vascular wall, which causes total or subtotal occlusion of the coronary arteries. Clinically, spasm is one of the MINOCAs, grouped under type 2 MI. The presence of an area of regional infarction in the myocardium could point towards spasm in the artery when no other explanation for the infarction is provided. It can affect either the epicardial arteries, as initially proposed by Prinzmetal et al. ([26] or the microcirculation, or both. The most frequent pathologic substrate of CAS is atherosclerotic CAD, but it has also rarely been reported in normal vessels [27]. Imaging tools such as computerized tomographic angiography (CTA), intravascular ultrasound (IVUS) and optical coherence tomography (OCT) show that the coronary artery segments where spasm is inducible are typically characterized by diffuse intimal and medial thickening with low lipid or calcium content, negative remodelling and small luminal area $[28,29]$. These features are in line with the hypothesis that vascular smooth muscle cell hyper-reactivity is a pathophysiological substrate for spasm [30]. Spasm and plaques are certainly not mutually exclusive features; spasms have been documented distal to stable plaques, in plaque-free segments bordering large eccentric plaques, and may serve as a 'rupture trigger' by inducing a plaque rupture followed by thrombosis in 'high-risk' plaques. Clinically, the combination of severe CAD and spasm is associated with adverse prognosis [31]. At autopsy, there are no distinctive gross or histologic hallmarks of CAS; thus, the possible morphologic substrates associated with an increased risk of spasm must be searched for, as well as microscopic evidence of ischemia. Drugs (cocaine, amphetamine and derivatives, androgenic anabolic steroids, chemotherapy), physical and mental stress and release of vasoconstrictor agents by activated platelets (mural thrombus) are considered precipitating factors of spasm [32-35]. Very rarely, CAS can occur in the setting of allergic/hypersensitivity reactions, which is known as Kounis Syndrome and histologically characterized by presence of eosinophils [36].

\section{Small vessel diseases}

Small vessel diseases (SVD) can occur without obvious structural changes of the heart. Microvascular dysfunction (MVD) is a functional impairment of pressure and flow in intramyocardial
Fig. 1 Coronary artery segments with different degrees of atherosclerotic stenosis. The diagrams demonstrate a $50 \%$ area stenosis, $75 \%$ stenosis and $90 \%$ stenosis; diameter $x$ will usually be less than $2 \mathrm{~mm}$ in the left main stem and less than $1 \mathrm{~mm}$ in other major coronary arteries

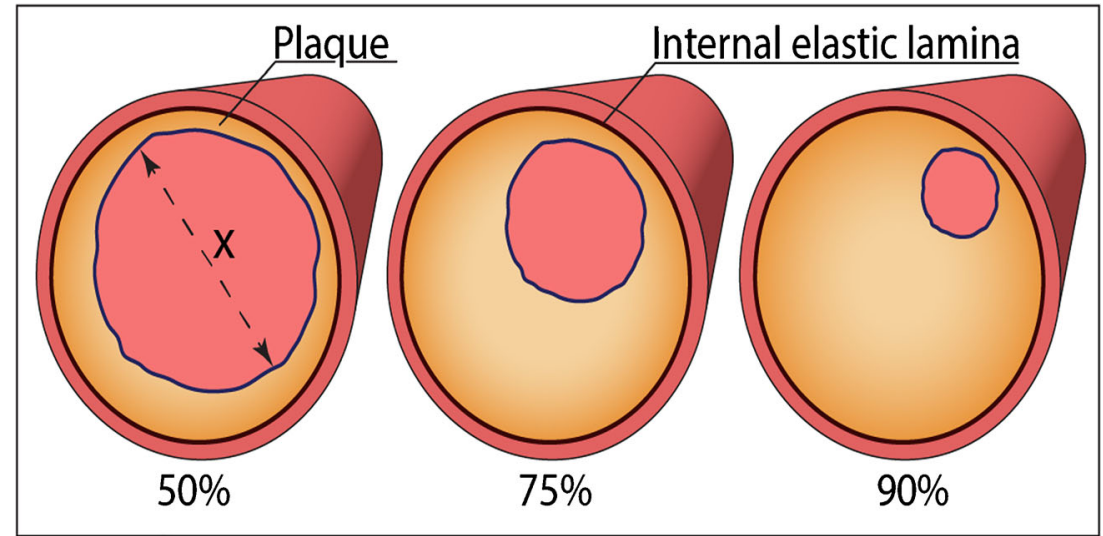


vessels $<500 \mu \mathrm{m}$ in diameter, and may cause MI. It is particularly seen in hypertrophic and dilated hearts, preferentially in the subendocardial areas of the myocardium. SVD is also a common feature in diabetic hearts and hearts of patients with longstanding hypertension, but structural changes such as some vascular wall thickening, if present, are difficult to interpret in practice and subject to interpretation bias. More rarely, structural diseases of intramyocardial vessels may be identifiable which include vasculitis, amyloidosis, small vessel type fibromuscular dysplasia, of which the latter can be isolated or in association with hypertrophic cardiomyopathy (HCM) or Fabry's disease [37-39]. It is important to note that in all these instances, myocardial areas with reduced flow due to concomitant epicardial (large vessel) coronary stenosis are most vulnerable. In transplanted hearts, SVD can be caused by widespread small vessel stenosis due to cardiac allograft vasculopathy [40]. Microvascular coronary embolization with thromboembolic materials distal to a thrombosed epicardial plaque can be found at autopsy in patients who died of MI [16, 39, 41] and occur nowadays even more frequently in acute MI patients who are treated with primary percutaneous coronary intervention (PCI) for acutely thrombosed plaques. In clinical studies, such emboli are an uncommon cause of acute MI, although they may result in microinfarctions occurring scattered through the myocardium. In later stages, they may leave small areas of replacement fibrosis. Moreover, microvascular embolization can occur in patients with atrial fibrillation, prosthetic heart valves, infective endocarditis or cardiac myxoma.

\section{latrogenic pathology of the coronary arteries}

Progressive stenosis or acute thrombotic occlusion of a coronary artery can be treated by means of $P C I$ in order to prolong life, to relieve symptoms, or minimize myocardial necrosis. At present, nearly all PCI procedures involve implantation of a metal stent or more recently, bioresorbable scaffolds (BRS). Stent-related complications, which are thrombosis and fibrocellular restenosis, have reduced significantly over the past years, mainly due to widespread application of drugeluting stents (DES) [42]. Acute stent thrombosis is very rare and may occur due to stent malposition, dissection, long or angulated stented segments, or sometimes due to hypersensitivity reactions. Late stent thrombosis, occurring even more than a year after placement, also remains a rare but lifethreatening complication in approximately $2 \%$ of patients and is mostly due to impaired neointimal covering of the coated stent and withdrawal of anti-platelet therapy [42]. Moreover, fibrocellular restenosis remains a problem in the still large group of patients, worldwide treated with noncoated bare metal stents (BMS). A more recently described long-term complication is the occurrence of in-stent neoatherosclerosis. Stent-related pathologies are coronary causes of the clinical type $4 \mathrm{MI}$. Autologous vein grafts or mammary arteries, which are used for CABG procedures, should also be examined carefully. A patent graft at autopsy is normally an empty collapsed vessel. Acute graft thrombosis can be due to technical failure at anastomosis sites, low left ventricular output failure or poor run-off in the distal vascular bed. Vein grafts may develop diffuse concentric intimal lesions within a few years, eventually complicated by thrombotic occlusion. Mammary arteries are particularly resistant to the development of intimal hyperplasia or neoatherosclerosis. Both in cases of PCI or CABG-related MI (clinical types MI 4 and 5), application of post-mortem coronary angiography should be considered. This method enables to localize stents, to visualize the patency of stents and grafts, and to evaluate the run off into the distal arterial bed and presence of collateral vascularization. Histological sampling of the jeopardized myocardium is crucial to investigate the presence of any form of myocardial injury as will be discussed later.

\section{Myocardial pathology in relation to ischemic death}

Irreversible damage of cardiomyocytes is the hallmark of MI, and results in ischemic necrosis, which is histologically 'coagulative type' necrosis. It should be discriminated from another type of necrosis that can be found regularly at autopsy, the 'contraction band type' of necrosis, which is a feature of many other forms of myocardial injury. For completeness, it should be mentioned that autophagy and apoptosis also occur during myocardial injury, but they are of less significance for daily practice, and will not further discussed.

\section{Evolution of myocardial necrosis in prolonged ischemic conditions}

The onset of ischemic necrosis is not immediate. In animal studies, using controlled occlusion of coronary arteries in healthy hearts, irreversible myocardial ischemia can be detected after $20 \mathrm{~min}$ [43]. In humans at autopsy, in which preexistent (ischemic) diseased hearts are not uncommon, timing is less certain. Ischemic necrosis of myocardial cells can be detected reliably with the current diagnostic methods after circa 2-4 h, but the onset depends on many variables such as collateral circulation, ischemic preconditioning and microvascular pathology. After the onset of occlusion, myocardial necrosis evolves in a wave front-like pattern over several hours from the endocardium to the epicardium [44, 45]. This implies that the loss of viable myocardium in the 'area at risk' (perfusion area of the occluded artery) gradually increases, finally ending up in a transmural MI. Therefore, in clinical cardiology, it is of pivotal importance to open the occluded artery by means of PCI or thrombolysis as early as possible, and reduce the size of the MI or even prevent it ('time is muscle'). During the evolving wave of myocardial necrosis, ventricular arrhythmias may occur in the subendocardium, 
even at the earliest stage of still reversibly damaged myocardium, but also several hours after occlusion when the wave of necrosis has evolved substantially. This is also important for pathologists to realize: early onset arrhythmia and SCD will reveal only early signs of myocardial injury or no changes at all, whereas later on in the wave of developing myocardial necrosis, a full-blown infarction can be visualized at histology. It should also be noted that later stages of myocardial necrosis and even old fibrotic scars can serve as a substrate for lifethreatening arrhythmias [46].

\section{Topographic distribution of $\mathrm{MI}$ in the heart}

According to the myocardial region involved, MI is classified as either regional when it involves the perfusion area of one epicardial artery, or circumferential when it encompasses the largest part of the circumference of the ventricular wall. Regional MI can be either transmural, usually associated with ST segment elevations on ecg (STEMI), or only subendocardial (non-STEMI). Early reperfusion interrupts the wave front of necrosis, which limits irreversible damage to the subendocardial region only (Fig. 2). The topography of segmental MI corresponds grossly to the perfusion territory of the three large epicardial arteries or, more rarely, one of their branches such as the first diagonal branch or the obtuse marginal artery. Occlusion of the left main stem usually results in immediate death. However, in the presence of extensive collateral circulation, which occurs frequently in chronically ischemic hearts, the association between site/extent of necrosis and the occluded branch is often less obvious ('paradoxical infarction'). Application of post-mortem angiography to the excised heart or during whole body post-mortem CT-angiography
(PMCTA) can provide important information on the presence and extent of collaterals between the vascular beds of major epicardial arteries (shown by a retrograde filling pattern), or neovascularization around chronic total occlusions ('bridging collaterals') (Fig. 3). Circumferential MI is mostly due to an overall fall in coronary perfusion pressure, often in the presence of severe multivessel CAD and involves in many cases only the subendocardial region.

Aberrant patterns of ischemic damage such as disseminated or predominantly epicardial locations have been reported in patients who died after resuscitation (see later) or in a setting of septic shock. In the latter, ischemia likely results from inflammation-related microvascular spasm, damage or thrombotic occlusions [47].

Atrial infarctions occur in combination with ventricular infarctions and have variable reported incidence among MI patients ranging from 0.7 to $42 \%$. Isolated atrial infarctions are scarce. The leading cause of atrial MI is coronary atherosclerosis. Pathologic significance is obviously lower than in ventricular infarctions, but for a pathologist, two potential complications of atrial MI should be underlined. The first is mural thrombus formation followed by thromboembolization, mostly pulmonary emboli ( $>80 \%$ of atrial infarctions are located in right atrium), and the second, the rare cases of atrial rupture that can result in cardiac tamponade [48].

\section{Post-mortem diagnosis of MI: gross, enzymatic and (immune) histological changes}

Many attempts have been undertaken to identify irreversible myocardial ischemia as accurately as possible and to discriminate myocardial ischemia from other forms of myocardial
Fig. 2 Patterns of topographic distribution of MI in the heart: regional transmural infarction; regional subendocardial infarction; circumferential subendocardial infarction; diffuse multifocal infarction

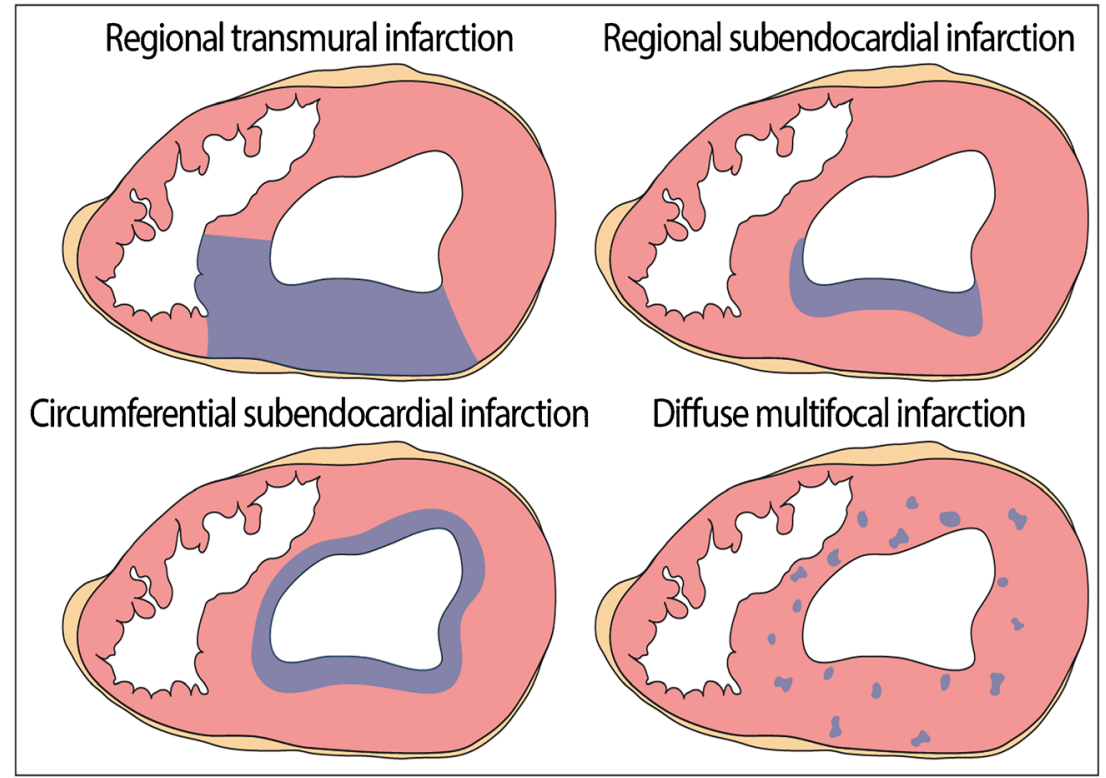


Fig. 3 Visualization of coronary collaterals in post-mortem angiograms. Contrast filling of right coronary artery (RCA) shows retrograde filling through collaterals of a large marginal branch of occluded left coronary artery (a). Contrast filling of RCA of another heart shows extensive 'bridging collaterals' surrounding a chronic total occlusion of the artery (b)
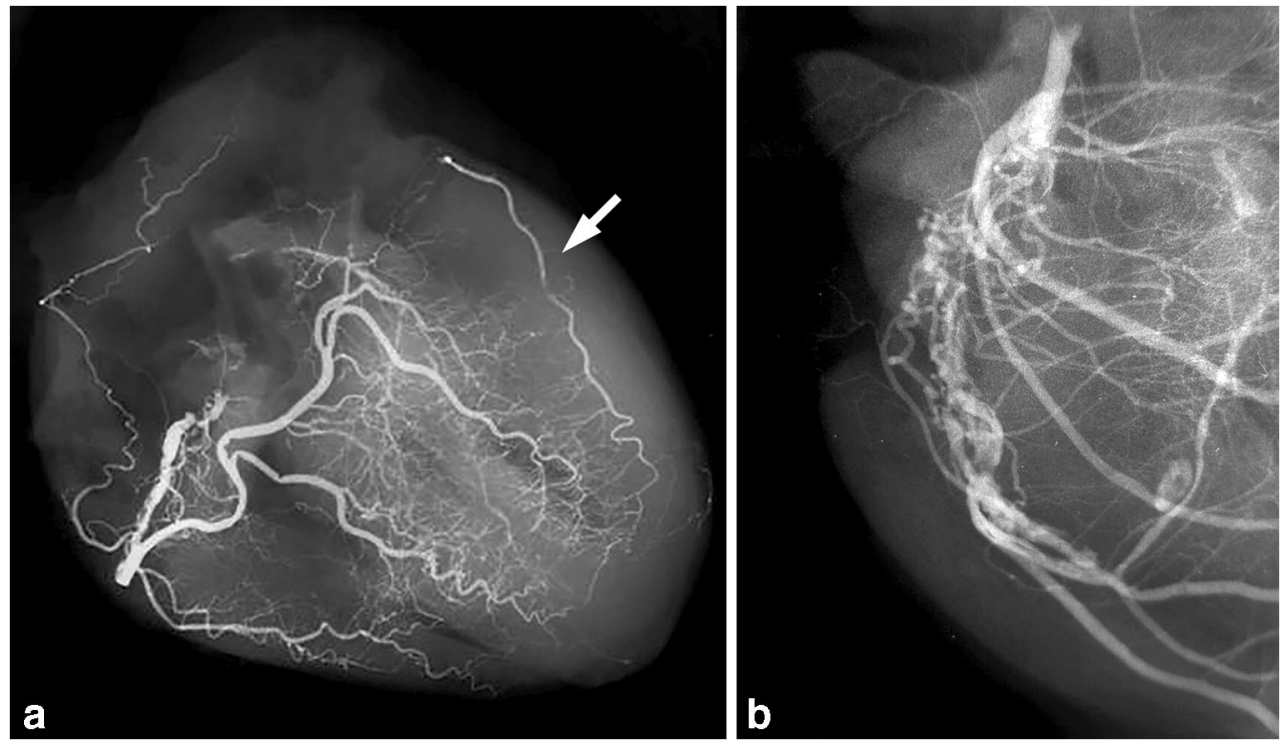

injury. Obviously, this information can be crucial in cases of sudden death, natural or accidental, witnessed or unwitnessed in forensic pathology, but also in case of deaths around the time of therapeutic coronary interventions or other medical investigations. Timing of the cellular events based on autopsy observations in humans has been described in detail in old original publications $[49,50]$ and also in textbooks of pathology $[51,52]$. They are summarized in Table 4 and illustrated in Fig. 4. However, when applying the listed histological parameters to estimate the age of $\mathrm{MI}$, it should be noted that many of them overlap, and, most importantly, they are subject to many factors that could affect the timing (Table 5). These factors include the age of the patient, the size of the infarction, ongoing inflammatory diseases and disorders of immunity; and local cardiac factors, including collateral circulation, ischemic pre-conditioning, repeated ischemic insults and reperfusion of the ischemic area. Changes occurring during cardiopulmonary resuscitation (CPR) and autolysis can mimic the early histologic changes of MI [5]. Therefore, more reliable clinic-pathological correlations can be drawn at autopsy by aiming to discriminate between four stages of injury and repair that relate to important clinical scenarios of ischemic morbidity and death. These four stages are:

1. Earliest stage of cell death (first hours): transmission electron microscopy (TEM) reveals very early ischemic changes such as mitochondrial swelling and sarcolemmal disruptions in cardiomyocytes occurring already $10 \mathrm{~min}$ after

Table 4 Histologic parameters of tissue damage and repair overtime in myocardial infarction (without reperfusion); see text for references

\begin{tabular}{|c|c|c|c|}
\hline $\begin{array}{l}\text { Myocardial histologic parameters } \\
\text { (HE staining) }\end{array}$ & Earliest manifestation & Full development & Decrease/disappearance \\
\hline Streched/wavy fibres & $1-2 \mathrm{~h}$ & & \\
\hline Coagulative necrosis: 'hypereosinophilia' & $1-3 \mathrm{~h}$ & $\begin{array}{l}\text { 1-3 days; hyper-eosinophilia and loss of } \\
\text { striations }\end{array}$ & $>3$ days: disintegration \\
\hline Interstitial oedema & $4-12 \mathrm{~h}$ & & \\
\hline Coagulative necrosis: 'nuclear changes' & 12-24 (pyknosis, karyorrhexis) & 1-3 days (loss of nuclei) & Depends on size of infarction \\
\hline PMN infiltration & $12-24 \mathrm{~h}$ & $1-3$ days & 5-7 days \\
\hline PMN karyorrhexis & $1.5-2$ days & $3-5$ days & \\
\hline Macrophages and lymphocytes & 3-5 days & 5-10 days (including 'siderophages') & 10 days to 2 months \\
\hline Vessel/endothelial sprouts* & 5-10 days & 10 days -4 weeks & $\begin{array}{l}4 \text { weeks: disappearance } \\
\text { of capillaries; some large } \\
\text { dilated vessels persist }\end{array}$ \\
\hline Fibroblast and young collagen* & 5-10 days & 2-4 weeks & $\begin{array}{l}\text { After } 4 \text { weeks; depends on } \\
\text { size of infarction; }\end{array}$ \\
\hline Dense fibrosis & 4 weeks & $2-3$ months & No \\
\hline
\end{tabular}

\footnotetext{
*Some authors summarize the vascular and early fibrotic changes as 'granulation tissue', which is maximal at 2-3 weeks
} 
Fig. 4 Histological features of MI at different stages, without reperfusion; myofiber waviness (a); interstitial oedema (b); hypereosinophilia and coagulative necrosis of cardiomyocytes (c); heavy granulocyte infiltration with karyorrhexis (d); macrophages and lymphocyte infiltration with early removal of necrotic debris (e); granulation tissue with formation of microvessels (f); fibroblast proliferation and early collagen deposition (g); dense fibrous scar replacing myocyte loss (h). All sections are stained with haematoxylin and eosin
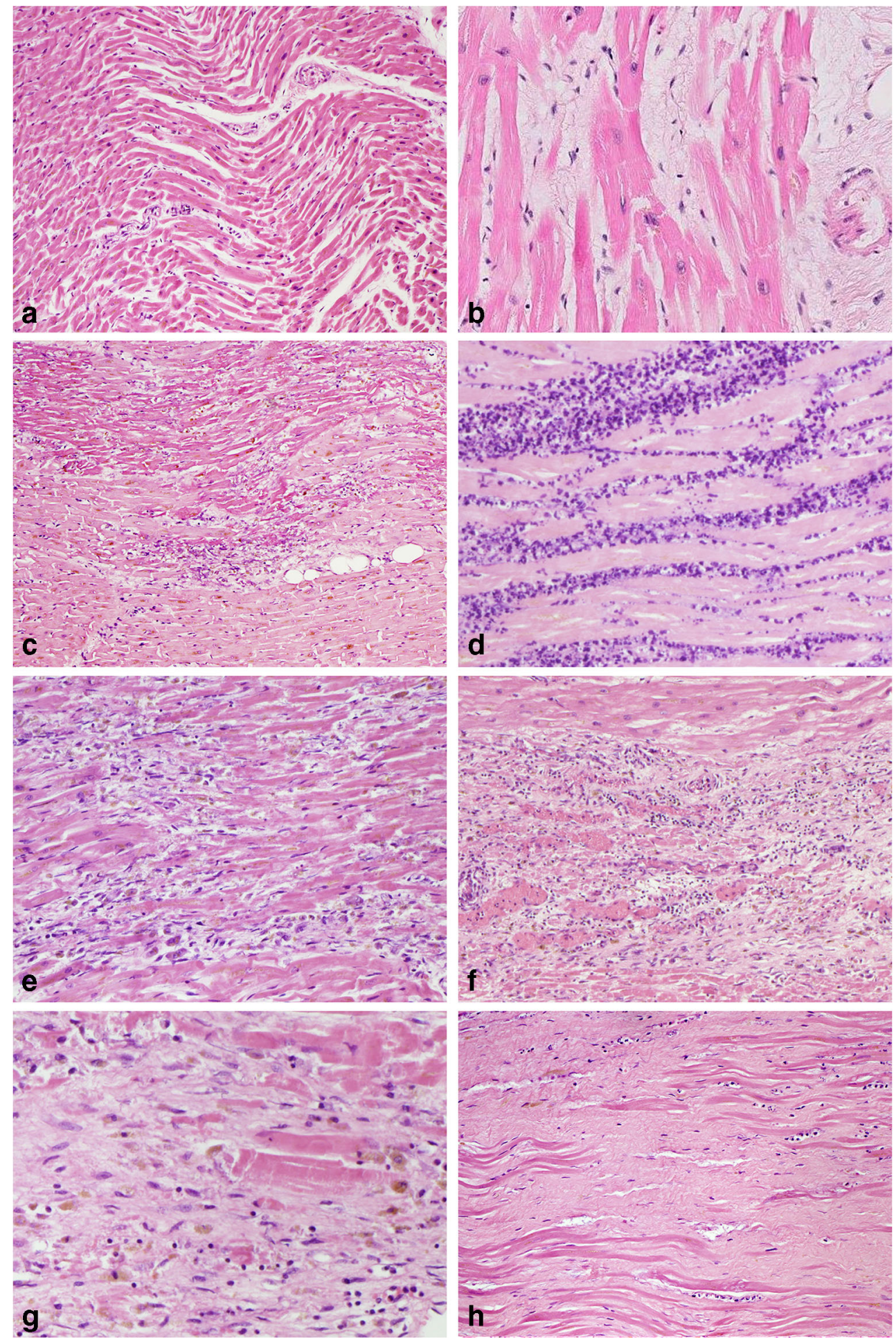

onset. However, this method can only be used in experimental conditions [53] and is not useful to detect early human ischemia because of the similarities between early ischemic changes and autolysis. Earliest light microscopic changes are a regional wavy pattern of myocytes as a result of stretching of dead non-contractile myocytes by adjacent functional myocardium during the cardiac cycle [50]. In the first hours, interstitial oedema and early onset of coagulative necrosis shown by cytoplasmic hyper eosinophilia also appear. However, these changes may have poor reliability in some instances and are subject to over-interpretation.

2. Inflammatory stage (first week): infiltration of neutrophils begins at MI borders. Neutrophils can also invade the central area of a small MI, but this happens much later 
Table 5 Diagnostic pitfalls in post-mortem diagnosis of myocardial ischemia

\begin{tabular}{|c|c|c|}
\hline Diagnostic method & Finding & Possible pitfalls \\
\hline \multirow[t]{2}{*}{$\begin{array}{l}\text { Histological } \\
\text { examination }\end{array}$} & Contraction bands & $\begin{array}{l}\text { Marker for ischemia/reperfusion (including border zones of ischemic infarctions), and } \\
\text { other types of myocardial injury }\end{array}$ \\
\hline & $\begin{array}{l}\text { Histopathological timing of } \\
\text { ischemia/infarction }\end{array}$ & $\begin{array}{l}\text { Evolution may be affected by several variables (individual heterogeneity in the response } \\
\text { to injury, repair and inflammatory response, size of infarction and medications that } \\
\text { affect inflammation and wound healing, collateral circulation) } \\
\text { Resuscitation trauma and autolysis can mimic histologic features of early MI (false } \\
\text { positivity). }\end{array}$ \\
\hline Immunohistochemistry & $\begin{array}{l}\text { Some antibodies may have low } \\
\text { sensitivity/specificity for early } \\
\text { ischemic necrosis }\end{array}$ & $\begin{array}{l}\text { Stains also other forms of myocardial injury; influenced by autolysis and post-mortem } \\
\text { interval; probably early detection, but exact time of onset of immunopositivity not } \\
\text { exactly known } \\
\text { Can occur in cases with long post-mortem interval }\end{array}$ \\
\hline $\begin{array}{l}\text { Nitro blue tetrazolium } \\
\text { (NBT) staining }\end{array}$ & Diffuse or spotty discoloration & $\begin{array}{l}\text { Unstained areas can occur in cases of long post-mortem interval, resuscitation attempts, } \\
\text { sepsis, technical failures (see text) }\end{array}$ \\
\hline \multirow[t]{4}{*}{ Post-mortem imaging } & Calcifications in PMCT & $\begin{array}{l}\text { Heavily calcified coronaries can be observed in stable plaques, not necessarily related to } \\
\text { acute coronary syndromes and MI } \\
\text { Non-calcified coronaries or spotty calcifications of coronaries might be observed in } \\
\text { eroded plaques }\end{array}$ \\
\hline & Perfusion of coronaries in PMCTA & $\begin{array}{l}\text { Difficult to discriminate thrombus from post-mortem clot } \\
\text { Some thrombosed coronary arteries (eroded plaques) might be perfused (mural thrombi) } \\
\text { Difficult to evaluate the perfusion of heavily calcified coronaries }\end{array}$ \\
\hline & Interstitial oedema in PMMR & $\begin{array}{l}\text { Also positive in other forms of injury, including CPR, and may occur as post-mortem } \\
\text { alteration }\end{array}$ \\
\hline & Increased enhancement in PMCTA & Can be influenced by resuscitation and post-mortem alteration \\
\hline Cardiac biomarkers & Increased of hs-TnT in serum & $\begin{array}{l}\text { Serum value can be influenced by post-mortem alteration } \\
\text { Cut-off of vital myocardial injury unknown }\end{array}$ \\
\hline
\end{tabular}

depending on the size of the infarction. Coagulation necrosis proceeds by showing the changes of further nuclear and myocyte disintegration. This coincides with heavy interstitial infiltrates of neutrophils and karyorrhexis of the neutrophils. Macroscopically, it acquires greyyellowish colour. At this stage, necrotic myocardium is weak and vulnerable to septal, papillary muscle or free wall ruptures in case of transmural infarctions, all with high mortality. Early phagocytosis of dead cells by macrophages, infiltration of other mononuclear cells such as lymphocytes and onset of a marginal fibrovascular response highlight further continuation of the healing process. However, in large MIs, residual necrotic areas can still be detected even after many weeks.

3. Granulation tissue stage ( 1 week to several weeks): this stage features capillary sprouting and ingrowth of fibroblasts with initial deposition of loosely arranged collagen fibres, and a persistent inflammatory infiltrate of lymphocytes, sparse plasma cells, macrophages including siderophages, whereas the number of neutrophils decreases. Granulation tissue is most abundant at 2-3 weeks. Grossly, this can be seen as a gelatinous hyperaemic border around the necrosis.

4. Late fibrotic (scarring) stage (beyond several weeks): the granulation tissue disappears gradually and is replaced by dense collagen leading to fibrotic scars, which usually contains dilated thin-walled vessels. The rate of disappearance of granulation tissue depends on the size of the MI but is completed by the second month in most instances, leaving a hypocellular compact scar.

\section{Enzymatic detection of early necrosis in fresh myocardium}

Nitro blue tetrazolium (NBT) staining of a fresh myocardial slice demonstrates early ischemic necrosis and is reported to be positive from $3 \mathrm{~h}$ after onset of ischemia. NBT stains only in the presence of intracellular lactate dehydrogenase (LDH). Leakage of enzymes from irreversibly injured myocardium appears as an unstained area in the otherwise deep purple stained vital myocardium [50, 51] [5] (Fig. 5). Unstained areas are not fully specific for MI, but can be caused also by other forms of injury although usually not in a distinct regional pattern. In addition, NBT staining is reported to be somewhat vulnerable to artefacts with false positivity in case of technical failure (inappropriate temperature or incubation time, formalin contamination), or situations like sepsis, CPR or long post-mortem intervals. 


\section{Immunohistochemistry of myocardium}

Several immunohistochemical markers have been investigated for the diagnosis of early MI, mostly markers for proteins that accumulate (such as fibronectin and C5b-9) or leak out of (such as troponins, myoglobin, S100A1) cardiomyocytes following ischemia. Other protein markers have been shown to undergo early changes in their phosphorylation state, as is demonstrated for connexin 43 [54, 55]. Markers/mediators of early inflammation (CD15, IL-6, TNF- $\alpha$, IL-15, IL-8, CD18 and tryptase) have also been proposed [56]. Some of them are promising in terms of early expression and specificity (dephosphorylated connexin 43), but they have been mainly investigated in experimental models [55]. When tested in human post-mortem samples, these markers keep their early expression profile, but lose their specificity [4]. Therefore, further investigations are needed before their eventual introduction in routine. Moreover, several pathologic or iatrogenic states such as CPR (including injection of catecholamines), autolysis, pre-existing ischemic events and medical treatments $[4,55]$ may influence the staining pattern and can interfere

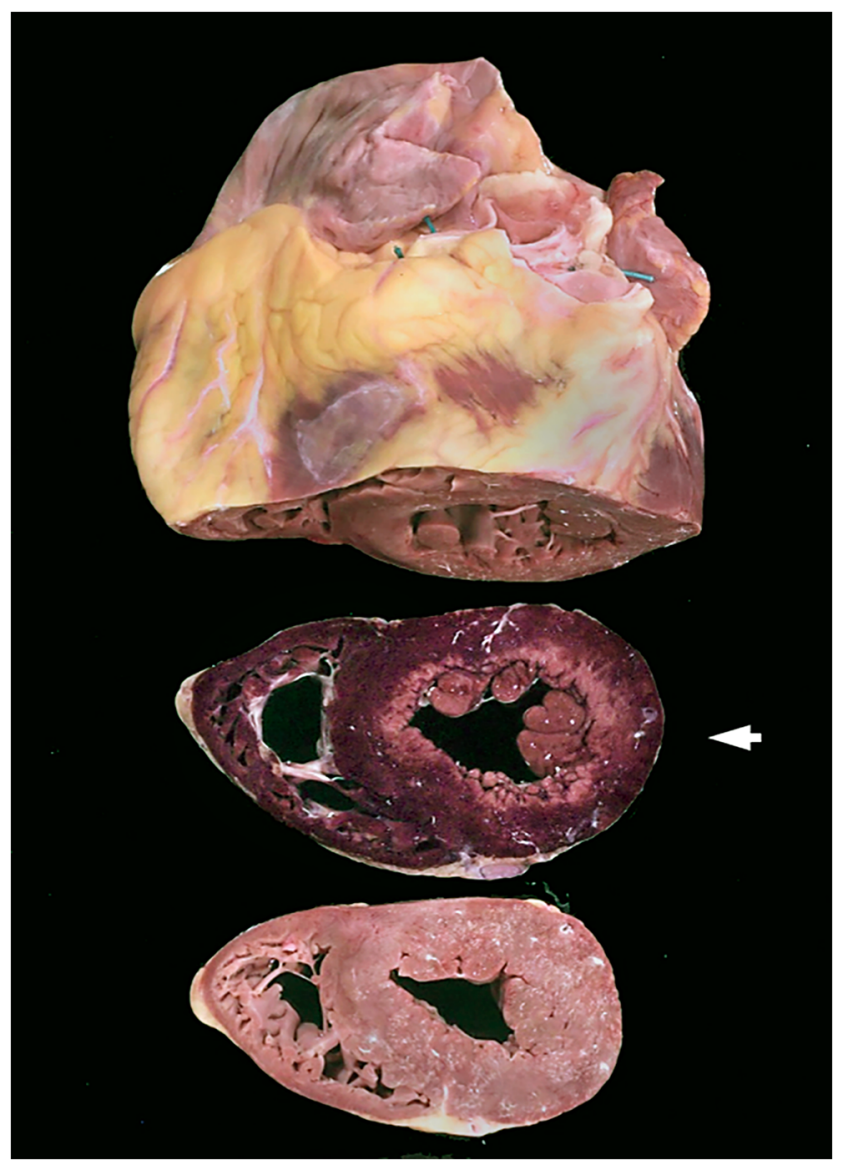

Fig. 5 Nitro blue tetrazolium (NBT)-stained myocardium; myocardial slice (middle) with circumferential subendocardial infarction indicated by loss of staining (pale area); purple-stained tissue represents vital myocardium, heart and apical slice are not NBT treated with a diagnosis of ischemic injury. Currently, a diagnosis of early myocardial injury in absence of changes in H\&E stains could be based on a combination of fibronectin and C5b-9 immune stains (Fig. 6). C5b-9 staining is more sensitive and specific than fibronectin staining, but fibronectin positivity starts earlier than C5b-9 [55]. In most cardiac transplant centres, C4d immunostaining is used routinely to detect myocardial injury on paraffin sections but the exact timing is unknown (Fig. 6). A larger panel of markers, simultaneously detected in the same tissue section (multiplexing), and quantification of their expression could improve the diagnostics of early myocardial ischemia, as has recently been shown by employing mass spectrometry immunohistochemistry [57].

\section{Ischemia and reperfusion and other forms of injury}

Myocardial and microvascular pathology after coronary intervention are closely related and the most important manifestations are peri-procedural ischemia, myocardial reperfusion injury and no-reflow phenomena, in combination with preexistent ischemic pathology of the myocardial area at risk [58].

Contraction band necrosis (CBN) of myocytes is the earliest sign of myocardial injury, which arises circa $10 \mathrm{~min}$ after onset of ischemia and reperfusion, and is characterized by the occurrence of thick eosinophilic bands in the cytoplasm of cardiomyocytes due to clustering of hypercontracted contractile proteins (Fig. 7a). After restoration of flow (reperfusion), dying cardiomyocytes with ischemically damaged cell membranes are exposed to high serum $\mathrm{Ca}^{2+}$ concentrations, leading to massive $\mathrm{Ca}^{2+}$ influx followed by irreversible hypercontraction $(\mathrm{CBN})$. It is important to note that contraction bands are not a feature of ischemic infarction alone, but still, they occur frequently in the periphery (the 'borderzones') of ischemic infarctions, which is due to microvascular collateral perfusion from adjacent vital myocardium. Caution should also be taken with the interpretation of presence of $\mathrm{CBN}$, since they can also be observed after CPR including defibrillation and other trauma. Not specifically related to PCI, but clearly of importance in a forensic setting, CBN has been observed in situations of catecholamine excess, drowning, drug abuse, cobalt poisoning, starvation, free radical injuries, brain death and intracerebral haemorrhage [59]. CBN is accompanied by microvascular injury leading to endothelial swelling, microvascular obstruction and interstitial haemorrhages (Fig. 7b, c). Influx of granulocytes is usually more pronounced when compared with non-reperfused MI, since granulocytes invade throughout the reperfused area.

'No-reflow' is a clinically defined feature entailing absence of tissue perfusion despite epicardial coronary patency and flow after PCI or CABG. It is due to microvascular damage, endothelial swelling, platelet plugging and spasm. In addition, distal embolization of fragile thrombus fragments and lipid 
Fig. 6 Immunostaining of early myocardial infarction. Positive staining for fibronectin (a) and C5b-9 (b) in irreversibly injured cardiomyocytes. Scale bars = $50 \mu \mathrm{m}$. Courtesy from Aljakna et al., Int J Legal Med, 2018; acute myocardial infarction in papillary muscle immunostained with C4d antibody (brown). Low power view, $b a r=0.25 \mathrm{~mm}$, highlights exact delineation of necrotic areas (geographic zones, and multifocal cells) (c); Higher magnification, bar $=50 \mu \mathrm{m}$, shows abrupt border between vital tissue and necrotic area (d)
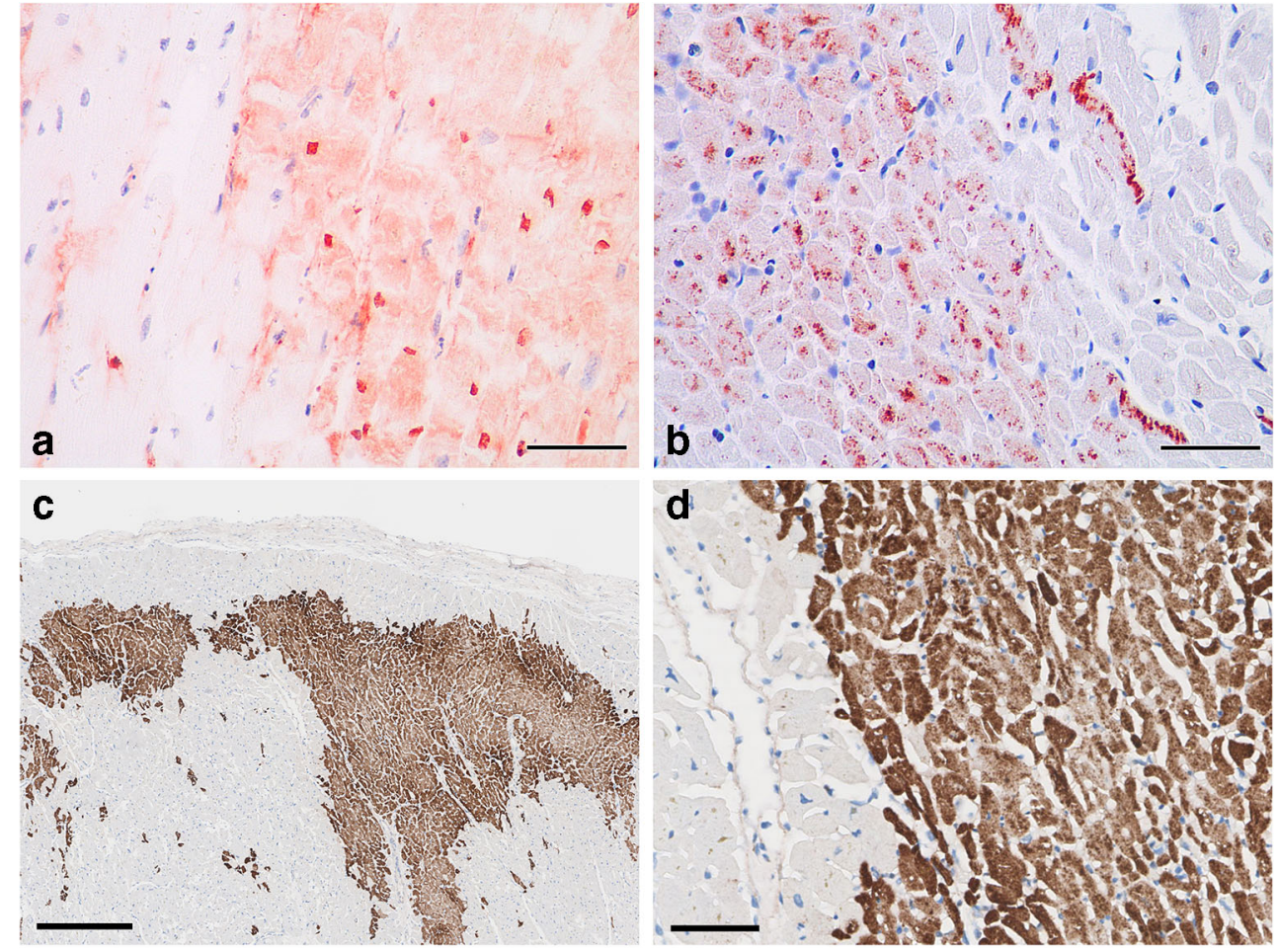

debris from the site of PCI may contribute to no-reflow of even microinfarctions. Recent investigations also suggest a role for embolization of the hydrophilic coating of guidewires used during PCI procedures such as stent implantation. At autopsy, such emboli are observed in myocardium distal to the site of PCI-treated culprit lesions, and in the longer term can be surrounded by inflammatory cells including foreign body giant cells (Fig. 7d) [60].

\section{$\mathrm{MI}$ in relation to hypertrophy and dilatation of the heart}

Myocardial oxygen consumption is proportional to ventricular muscle mass, wall stress, heart rate and contractility. In hypertrophic and dilated hearts, and especially in combination with coronary stenosis, tachycardia may significantly contribute to symptoms such as effort type of angina or even sudden death. At autopsy, any circumstances of death that may have provoked tachycardia are informative [61]. The relationship between myocardial mass and oxygen demand is linear, so a doubling in mass doubles oxygen demand. In athletes, the adaptive changes in the heart ensure that the balance between oxygen supply and demand is maintained [62]. However, in pathological conditions such as hypertension, aortic stenosis and cardiomyopathy, oxygen consumption increases out of proportion to supply. According to the Laplace equation, ventricular wall stress is proportional to chamber pressure and radius, and inversely proportional to wall thickness. Dilated hearts with volume overload (large chamber, thin ventricular wall) may display substantially increased wall stresses, which require high coronary perfusion gradients for optimal oxygenation [61]. In situations of increased demand, usually during exercise, this may evolve to myocardial ischemia, which is preferentially located in subendocardial layers, where microvascularization is less plentiful. Obviously, this situation worsens in combination with stenosis of epicardial coronary arteries by plaques that are frequently present in these patients [61]. In dilated cardiomyopathies (DCM), imaging studies using positron emission tomography (PET) have demonstrated this loss of myocardial blood flow reserve with changes indicating ischemia [63]. Chronic ischemia is thought to underlie the cytoplasmic clearing of subendocardial myocytes, often seen in dilated hearts and around old infarctions, which represents dysfunctional but still viable myocardium. Circumferential subendocardial infarctions can be observed regularly in the elderly population who died of hypertrophic or dilated hearts due to aortic valve stenosis (Fig. 5).

\section{Takotsubo syndrome}

Takotsubo syndrome (TTS) is a clinical syndrome in the spectrum of ischemic heart disease that is characterized by acute heart failure with transient regional myocardial wall motion abnormalities in the absence of culprit atherosclerotic CAD. Since the heart stands still after death, the typical shape of the heart that is observed during systole in Takotsubo syndrome cannot be detected after death. It is found in 1-2\% of patients presenting with suspected MI, mostly post-menopausal 
Fig. 7 Histological features of MI with reperfusion; Detail of myocardium with contraction band necrosis (a); microvascular damage and extravasation of erythrocytes (b); macroscopic image of the heart with left ventricular widespread circumferential subendocardial haemorrhage(c); embolus of guide wire coating (blue material) surrounded by giant cells and some lymphocytic infiltration in myocardial microvessel of a previously PCI treated (stented) coronary artery (d); Histologic sections stained with haematoxylin and eosin


women. In these patients, there is only a small elevation in troponin levels, not enough for the diagnosis of MI. The syndrome is frequently preceded by a stressful emotional or physical trigger or can be secondary to an underlying disease such as pheochromocytoma [64]. The cardiotoxic effects of high levels of catecholamines play a central role in the pathophysiology, but SVD and CAS may also contribute. Recently, it was suggested that autonomic-limbic dysfunction might play a crucial role in the pathophysiology of TTS [65]. The histopathology of TTS shows CBN and vacuolation of cardiomyocytes with widened interstitial space in the acute phase and recovery during follow-up. Individual cardiomyocyte cell death, macrophage reaction and scarring have also been described, predominantly in cases with an underlying pheochromocytoma with prolonged catecholamine effect [66].

\section{Resuscitation}

Subendocardial infarction is common following cardiac arrest and CPR with survival. Even when ventricular fibrillation occurs very early after the onset of ischemia, infarction becomes visible at autopsy because of life support long enough for structural myocardial changes to develop. When such patients eventually die with hypoxic brain damage or poor cardiac function, the infarct can be first noted in the subendocardium as irregular hemorrhagic areas due to reperfusion injury (Fig. 7c). In advanced cases, the whole circumference of the LV shows diffuse hemorrhagic infarction. Haemorrhage can obscure other features such as CBN and coagulative necrosis of the myocytes. Attention should be paid as the changes can sometimes be subtle and focal in the papillary muscle and trabeculae of the LV and rarely occur in the RV $[67,68]$. Macroscopic and microscopic signs of myocardial contusion following CPR (epicardial haemorrhage, patchy necrosis, blood blisters, oedema) have also been reported at autopsy without vital reaction [69]. Apart from aberrant location (epicardially, patchy, right ventricle), it can be difficult to discriminate these signs from ischemia and reperfusion due to infarction as described above.

\section{In situ post-mortem imaging of the heart}

Radiological post-mortem examination of ischemic heart permits the evaluation of morphological features of coronary arteries and myocardium, but without the possibility to perform functional radiological evaluation, as can be applied in vivo. These new methods can be a useful adjunct to autopsy, allowing a detailed documentation of the body before the dissection (of crucial importance for postsurgery forensic cases), and to direct to sites of tissue sampling. Some investigators suggest that post-mortem imaging and especially minimal invasive autopsy can even replace autopsy in case of a suspected MI [6, 70], but there are still limitations and controversies about its use in these situations $[6,7,70-72]$. In clinical practice, coronary artery calcium score represents an independent predictor of CAD events that correlates closely with overall atherosclerotic burden. Coronary calcifications are 
easily detectable by post-mortem computer tomography (PMCT) but their detection is not sufficient to attribute the death to myocardial ischemia. Thrombotic occlusions, especially on eroded plaques, can occur also on noncalcified plaques. Angiographic post-mortem methods enable evaluation of coronary artery lumen, detecting stenosis and suspected occlusions [70, 73]. Pre-stenotic dilatation, called napkin-ring sign, was recently described and considered to be the imaging correlate of a high-risk plaque. This sign was reported to possess a high predictive value for future cardiac events and was described in post-mortem cases although its diagnostic value is unknown [74]. PMCTA was shown as not a perfect replacement for the histological examination [73]. Radiological methods do not enable the certain differentiation between vital thrombus and post-mortem clot.

The interpretation of oedema in MI during life is considered as complicated and controversial today. An initial wave of oedema appears abruptly at reperfusion, significantly attenuated by $24 \mathrm{~h}$ and then followed by a second healing-related wave of oedema several days after reperfusion [75]. Post-mortem radiological evaluation of ischemic myocardium is extremely challenging. Multiphase CT angiography (MPMCTA) has been suggested to be able to detect infarcted areas as regions of pathological enhancement of the signal. This technique can be instrumental to identifying affected regions for histological sampling as is applied in minimally invasive autopsies [76]. It was suggested that post-mortem MR (PMMR) enables the detection of MI in situ and the estimation of infarct age based on signal behaviour [77, 78] and a combination of PMMR with heart biopsies was shown to have high sensitivity and specificity for the detection of MI [7]. At this time, there is still a need to validate these novels post-mortem imaging techniques by comparing them with autopsy findings on patients who died of ACS (see also Table 5).

\section{Post-mortem cardiac biomarkers}

Cardiac troponins (cTns) are the most frequently used biomarkers in clinical practice as they are most sensitive and specific for diagnosing cardiomyocyte injury $[9,79]$. In recent years, cTn measurement was replaced by the high-sensitivity cardiac troponin $\mathrm{T}$ (hs-TnT) assay, able to detect MI within $3 \mathrm{~h}$ after the onset $[79,80]$. However, the increased levels of hs$\mathrm{TnT}$ indicate presence of myocardial injury and are not specific for ischemia [80]. Therefore, the technique is of limited value to establish the exact cause of (cardiac) death. Serum levels do not show any correlation with any cause of death although low hs-TnT levels in pericardial fluid allow the exclusion of the heart damage [81]. A non-linear significant association between hs-TnT serum values and the presence of IHD as the cause of death was suggested, but a cut-off value as applies for in vivo could not be established, probably because of post-mortem alterations (Table 5). [82].

\section{Conclusions}

Clinical diagnosis of MI follows closely the new insights in pathophysiology derived from recent progresses in cardiac imaging, electrophysiology, biochemistry and coronary intervention. Pathologists should be aware of these insights in order to interpret their findings at autopsy appropriately. In most cases, the currently available diagnostic tools at autopsy appear appropriate for this purpose, but pitfalls in diagnosis should be considered (Table 5). Promising areas of investigation to increase diagnostic yield at autopsy are the new tissue markers of acute tissue injury (and reperfusion) and also whole-body postmortem imaging which is suggested to detect oedema as an early marker of myocardial injury, and can be instrumental in guiding minimally invasive autopsy techniques.

Acknowledgement On behalf of the Association for European Cardiovascular Pathology (AECVP)

Author contribution KM, CB, GdA, CG, IK, SDP, MNS, ACW designed the work. KM, CB, GdA, CG, IK, SDP, SR, SS, MNS, AV, ACW analysed and interpreted data, wrote and critically revised the article. The final version of the article was approved for publication also by all authors. KM and ACW take full responsibility for the work as a whole, including the study design and the decision to submit and publish the manuscript.

Compliance with ethical standards Ethical approval was not required for his study.

Conflict of interest The authors declare that they have no conflicts of interest.

List of abbreviations ACS, acute coronary syndrome; BRS, bioresorbable scaffolds; $\mathrm{CABG}$, coronary artery bypass graft; $\mathrm{CAD}$, coronary artery disease; CAS, coronary artery spasm; CPR, cardiopulmonary resuscitation; CRP, C-reactive protein; FMD, fibromuscular dysplasia; hs-TnT, high-sensitive cardiac troponin T; IHD, ischemic heart disease; LV, left ventricle; MI, myocardial infarction; MINOCA, myocardial infarction with no obstructive coronary atherosclerosis; MVD, microvascular dysfunction; NBT, nitro blue tetrazolium; PCI, percutaneous coronary intervention; PET, positron emission tomography; PMCT, post-mortem computed tomography; PMCTA, post-mortem CT angiography; PMMR, post-mortem magnetic resonance; RV, right ventricle; $S V D$, small vessels disease; SCD, sudden cardiac death; TTS, Takotsubo syndrome; TAVI, transcatheter aortic valve implantation; TEM, transmission electron microscopy; VF, ventricular fibrillation

Open Access This article is distributed under the terms of the Creative Commons Attribution 4.0 International License (http:// creativecommons.org/licenses/by/4.0/), which permits unrestricted use, distribution, and reproduction in any medium, provided you give 
appropriate credit to the original author(s) and the source, provide a link to the Creative Commons license, and indicate if changes were made.

\section{References}

1. Mendis S, Puska P, Norrving B (2011) Global atlas on cardiovascular disease prevention and control. World Health Organization. https://www.who.int/cardiovascular_diseases/publications/atlas cvd/en/. Accessed 09.082019

2. Wong CX, Brown A, Lau DH, Chugh SS, Albert CM, Kalman JM, Sanders P (2019) Epidemiology of sudden cardiac death: global and regional perspectives. Heart Lung Circ 28(1):6-14. https://doi.org/ 10.1016/j.hlc.2018.08.026

3. Basso C, Aguilera B, Banner J et al (2017) Guidelines for autopsy investigation of sudden cardiac death: 2017 update from the Association for European Cardiovascular Pathology. Virchows Arch 471(6):691-705. https://doi.org/10.1007/s00428-017-2221-0

4. Sabatasso S, Moretti M, Mangin P, Fracasso T (2018) Early markers of myocardial ischemia: from the experimental model to forensic pathology cases of sudden cardiac death. Int J Legal Med 132(1):197-203. https://doi.org/10.1007/s00414-017-1605-7

5. Vargas SO, Sampson BA, Schoen FJ (1999) Pathologic detection of early myocardial infarction: a critical review of the evolution and usefulness of modern techniques. Mod Pathol 12(6):635-645

6. Rutty GN, Morgan B, Robinson C, Raj V, Pakkal M, Amoroso J, Visser T, Saunders S, Biggs M, Hollingbury F, McGregor A, West K, Richards C, Brown L, Harrison R, Hew R (2017) Diagnostic accuracy of post-mortem CT with targeted coronary angiography versus autopsy for coroner-requested post-mortem investigations: a prospective, masked, comparison study. Lancet 390(10090):145154. https://doi.org/10.1016/S0140-6736(17)30333-1

7. Wagensveld IM, Blokker BM, Pezzato A, Wielopolski PA, Renken NS, von der Thüsen JH, Krestin GP, Hunink MGM, Oosterhuis JW, Weustink AC (2018) Diagnostic accuracy of postmortem computed tomography, magnetic resonance imaging, and computed tomography-guided biopsies for the detection of ischaemic heart disease in a hospital setting. Eur Heart J Cardiovasc Imaging 19(7):739-748. https://doi.org/10.1093/ehjci/jey015

8. van den Tweel JG, Wittekind C (2016) The medical autopsy as quality assurance tool in clinical medicine: dreams and realities. Virchows Arch 468(1):75-81. https://doi.org/10.1007/s00428015-1833-5

9. Thygesen K, Alpert JS, Jaffe AS, Chaitman BR, Bax JJ, Morrow DA, White HD, ESC Scientific Document Group, Thygesen K, Alpert JS, Jaffe AS, Chaitman BR, Bax JJ, Morrow DA, White HD, Mickley H, Crea F, van de Werf F, Bucciarelli-Ducci C, Katus HA, Pinto FJ, Antman EM, Hamm CW, de Caterina R, Januzzi JL Jr, Apple FS, Alonso Garcia MA, Underwood SR, Canty JM Jr, Lyon AR, Devereaux PJ, Zamorano JL, Lindahl B, Weintraub WS, Newby LK, Virmani R, Vranckx P, Cutlip D, Gibbons RJ, Smith SC, Atar D, Luepker RV, Robertson RM, Bonow RO, Steg PG, O'Gara PT, Fox KAA, Hasdai D, Aboyans V, Achenbach S, Agewall S, Alexander T, Avezum A, Barbato E, Bassand JP, Bates E, Bittl JA, Breithardt G, Bueno H, Bugiardini R, Cohen MG, Dangas G, de Lemos JA, Delgado V, Filippatos G, Fry E, Granger CB, Halvorsen S, Hlatky MA, Ibanez B, James S, Kastrati A, Leclercq C, Mahaffey KW, Mehta L, Müller C, Patrono C, Piepoli MF, Piñeiro D, Roffi M, Rubboli A, Sharma S, Simpson IA, Tendera M, Valgimigli M, van der Wal AC, Windecker S, Chettibi M, Hayrapetyan H, Roithinger FX, Aliyev F, Sujayeva V, Claeys MJ, Smajić E, Kala P, Iversen KK, el Hefny E, Marandi T, Porela P, Antov S, Gilard M, Blankenberg S, Davlouros P, Gudnason T, Alcalai R, Colivicchi F, Elezi S, Baitova G, Zakke I, Gustiene O, Beissel J, Dingli P, Grosu A,
Damman P, Juliebø V, Legutko J, Morais J, Tatu-Chitoiu G, Yakovlev A, Zavatta M, Nedeljkovic M, Radsel P, Sionis A, Jemberg T, Müller C, Abid L, Abaci A, Parkhomenko A, Corbett S (2019) Fourth universal definition of myocardial infarction (2018). Eur Heart J 40(3):237-269. https://doi.org/10.1093/ eurheartj/ehy462

10. Jangaard N, Sarkisian L, Saaby L et al (2017) Incidence, frequency, and clinical characteristics of type 3 myocardial infarction in clinical practice. Am J Med 130(7):862.e869-862.e814. https://doi.org/ 10.1016/j.amjmed.2016.12.034

11. Leone O, Pieroni M, Rapezzi C, Olivotto I (2019) The spectrum of myocarditis: from pathology to the clinics. Virchows Arch 475: 279-301. https://doi.org/10.1007/s00428-019-02615-8

12. Davies MJ (1992) Anatomic features in victims of sudden coronary death. Coronary artery pathology. Circulation (85):I19-I24

13. Farb A, Tang AL, Burke AP, Sessums L, Liang Y, Virmani R (1995) Sudden coronary death. Frequency of active coronary lesions, inactive coronary lesions, and myocardial infarction. Circulation 92(7):1701-1709. https://doi.org/10.1161/01.cir.92.7.1701

14. Kolodgie FD, Gold HK, Burke AP, Fowler DR, Kruth HS, Weber DK, Farb A, Guerrero LJ, Hayase M, Kutys R, Narula J, Finn AV, Virmani R (2003) Intraplaque hemorrhage and progression of coronary atheroma. N Engl J Med 349(24):2316-2325. https://doi.org/ 10.1056/NEJMoa035655

15. van der Wal A, Becker A (1999) Atherosclerotic plaque rupture pathologic basis of plaque stability and instability. Cardiovasc Res 41(2):334-344. https://doi.org/10.1016/s0008-6363(98)00276-4

16. Falk E, Nakano M, Bentzon JF, Finn AV, Virmani R (2013) Update on acute coronary syndromes: the pathologists' view. Eur Heart J 34(10):719-728. https://doi.org/10.1093/eurheartj/ehs411

17. Myerburg RJ, Junttila MJ (2012) Sudden cardiac death caused by coronary heart disease. Circulation 125(8):1043-1052. https://doi. org/10.1161/circulationaha.111.023846

18. Rittersma SZH, van der Wal AC, Koch KT, Piek JJ, Henriques JPS, Mulder KJ, Ploegmakers JPHM, Meesterman M, de Winter RJ (2005) Plaque instability frequently occurs days or weeks before occlusive coronary thrombosis. A pathological thrombectomy study in primary percutaneous coronary intervention. 111(9): 1160-1165. https://doi.org/10.1161/01.cir.0000157141.00778.ac

19. Henriques de Gouveia R, van der Wal AC, van der Loos CM, Becker AE (2002) Sudden unexpected death in young adults. Discrepancies between initiation of acute plaque complications and the onset of acute coronary death. Eur Heart J 23(18):14331440. https://doi.org/10.1053/euhj.2002.3159

20. Manwarring L, O'Connell DL, Bhagwandeen BS, Zardawi IM, Dobson AJ (1988) Morphometric analysis of coronary artery stenosis: an accuracy and reliability study. J Pathol 156(2):111-117. https://doi.org/10.1002/path.1711560205

21. Ford JC, O'Rourke K, Veinot JP, Walley VM (2000) Histologic estimation of coronary artery stenoses: reproducibility and the effect of training. Cardiovasc Pathol 9(5):251-255. https://doi.org/10. 1016/S1054-8807(00)00044-2

22. Ford JC, O'Rourke K, Veinot JP, Walley VM (2001) The histologic estimation of coronary artery stenoses: accuracy and the effect of lumen shape. Cardiovasc Pathol 10(2):91-96. https://doi.org/10. 1016/S1054-8807(01)00060-6

23. Pasterkamp G, Schoneveld AH, van der Wal AC, Haudenschild CC, Clarijs RJG, Becker AE, Hillen B, Borst C (1998) Relation of arterial geometry to luminal narrowing and histologic markers for plaque vulnerability: the remodeling paradox. J Am Coll Cardiol 32(3):655-662. https://doi.org/10.1016/S0735-1097(98) 00304-0

24. Maximilian Buja L, Willerson JT (1987) The role of coronary artery lesions in ischemic heart disease: insights from recent clinicopathologic, coronary arteriographic, and experimental studies. Hum 
Pathol 18(5):451-461. https://doi.org/10.1016/S0046-8177(87) 80030-8

25. Virmani R, Burke AP, Farb A (2001) Sudden cardiac death. Cardiovasc Pathol 10(5):211-218. https://doi.org/10.1016/S10548807(01)00091-6

26. Prinzmetal M, Kennamer R, Merliss R, Wada T, Bor N (1959) Angina pectoris I. A variant form of angina pectoris: preliminary report. Am J Med 27(3):375-388. https://doi.org/10.1016/00029343(59)90003-8

27. MacAlpin RN (2015) Some observations on and controversies about coronary arterial spasm. Int J Cardiol 181:389-398. https:// doi.org/10.1016/j.ijcard.2014.12.047

28. Morikawa Y, Uemura S, K-i I et al (2011) Morphological features of coronary arteries in patients with coronary spastic angina: assessment with intracoronary optical coherence tomography. Int $\mathbf{J}$ Cardiol 146(3):334-340. https://doi.org/10.1016/j.ijcard.2009.07. 011

29. Tsujita K, Sakamoto K, Kojima S, Kojima S, Takaoka N, Nagayoshi Y, Sakamoto T, Tayama S, Kaikita K, Hokimoto S, Sumida H, Sugiyama S, Nakamura S, Ogawa H (2013) Coronary plaque component in patients with vasospastic angina: a virtual histology intravascular ultrasound study. Int J Cardiol 168(3): 2411-2415. https://doi.org/10.1016/j.ijcard.2013.02.002

30. Rizzo S, Coen M, Sakic A, de Gaspari M, Thiene G, Gabbiani G, Basso C, Bochaton-Piallat ML (2018) Sudden coronary death in the young: evidence of contractile phenotype of smooth muscle cells in the culprit atherosclerotic plaque. Int J Cardiol 264:1-6. https://doi. org/10.1016/j.ijcard.2018.02.096

31. Slavich M, Patel RS (2016) Coronary artery spasm: current knowledge and residual uncertainties. Int J Cardiol Heart Vasc 10:47-53. https://doi.org/10.1016/j.ijcha.2016.01.003

32. Hung M-J, Hu P, Hung M-Y (2014) Coronary artery spasm: review and update. Int J Med Sci 11(11):1161-1171. https://doi.org/10. 7150/ijms. 9623

33. Lucena J, Blanco M, Jurado C, Rico A, Salguero M, Vazquez R, Thiene G, Basso C (2010) Cocaine-related sudden death: a prospective investigation in south-west Spain. Eur Heart J 31(3):318-329. https://doi.org/10.1093/eurheartj/ehp557

34. Baggish Aaron L, Weiner Rory B, Kanayama G et al (2017) Cardiovascular toxicity of illicit anabolic-androgenic steroid use. Circulation 135(21):1991-2002. https://doi.org/10.1161/ CIRCULATIONAHA.116.026945

35. Monsuez J-J, Charniot J-C, Vignat N, Artigou J-Y (2010) Cardiac side-effects of cancer chemotherapy. Int J Cardiol 144(1):3-15. https://doi.org/10.1016/j.ijcard.2010.03.003

36. Kounis NG (2013) Coronary hypersensitivity disorder: the Kounis syndrome. Clin Ther 35(5):563-571. https://doi.org/10.1016/j. clinthera.2013.02.022

37. Herrmann J, Kaski JC, Lerman A (2012) Coronary microvascular dysfunction in the clinical setting: from mystery to reality. Eur Heart J 33(22):2771-2782b. https://doi.org/10.1093/eurheartj/ehs246

38. James TN (1990) The spectrum of diseases of small coronery arteries and their physiologic consequences. J Am Coll Cardiol 15(4): 763-774. https://doi.org/10.1016/0735-1097(90)90272-Q

39. van der Wal AC (2007) Coronary artery pathology. Heart 93(11): 1484-1489. https://doi.org/10.1136/hrt.2004.038364

40. Lu W-h, Palatnik K, Fishbein GA et al (2011) Diverse morphologic manifestations of cardiac allograft vasculopathy: a pathologic study of 64 allograft hearts. J Heart Lung Transplant 30(9):1044-1050. https://doi.org/10.1016/j.healun.2011.04.008

41. Davies MJ (2000) The pathophysiology of acute coronary syndromes. Heart 83(3):361-366. https://doi.org/10.1136/heart.83.3. 361

42. Torrado J, Buckley L, Duran A et al (2018) Restenosis, stent thrombosis, and bleeding complications: navigating between Scylla and
Charybdis. J Am Coll Cardiol 71(15):1676-1695. https://doi.org/ 10.1016/j.jacc.2018.02.023

43. Thygesen K, Alpert JS, Jaffe AS, Chaitman BR, White HD (2018) Clarifying the proper definitions for type 2 myocardial infarction. $\mathrm{J}$ Am Coll Cardiol 71(11):1291. https://doi.org/10.1016/j.jacc.2017. 12.063

44. Reimer KA, Jennings RB (1979) Wavefront phenomenon of myocardial sschemic cell-death .2. Transmural progression of necrosis within the framework of ischemic bed size (myocardium at risk) and collateral flow. Lab Investig 40(6):633-644

45. Jennings RB, Ganote CE, Reimer KA (1975) Ischemic tissue injury. Am J Pathol 81(1):179-198

46. Bello D, Fieno DS, Kim RJ, Pereles FS, Passman R, Song G, Kadish AH, Goldberger JJ (2005) Infarct morphology identifies patients with substrate for sustained ventricular tachycardia. J Am Coll Cardiol 45(7):1104-1108. https://doi.org/10.1016/j.jacc.2004. 12.057

47. May AM, Riede FN, Riede U-N (2010) Acute subepicardial infarction associated with severe septic shock - insight in myocardial perfusion. Pathol Res Pract 206(6):401-404. https://doi.org/10. 1016/j.prp.2009.11.001

48. Lu ML, De Venecia T, Patnaik S, Figueredo VM (2016) Atrial myocardial infarction: a tale of the forgotten chamber. Int $\mathrm{J}$ Cardiol 202:904-909. https://doi.org/10.1016/j.ijcard.2015.10.070

49. Lodge-Patch I (1951) The ageing of cardiac infarcts, and its influence on cardiac rupture. Br Heart J 13(1):37-42. https://doi.org/10. 1136/hrt.13.1.37

50. Fishbein MC, Maclean D, Maroko PR (1978) The histopathologic evolution of myocardial infarction. Chest 73(6):843-849. https:// doi.org/10.1378/chest.73.6.843

51. Allen P. Burke FT (2011) Practical cardiovascular pathology. In: Allen P. Burke FT (ed). Lippincott Williams and Wilkins, Philadelphia, United States, $\mathrm{p} 90$

52. Kumar V, Abbas A, Fausto N, Aster J (2014) Robbins and Cotran pathologic basis of disease, 9th edition. Elsevier,

53. Kloner RA, Rude RE, Carlson N, Maroko PR, DeBoer LW, E B (1980) Ultrastructural evidence of microvascular damage and myocardial cell injury after coronary artery occlusion: which comes first. Circulation 62(5):945-952

54. Beardslee MA, Lerner DL, Tadros PN, Laing JG, Beyer EC, Yamada KA, Kléber ÁG, Schuessler RB, Saffitz JE (2000) Dephosphorylation and intracellular redistribution of ventricular connexin43 during electrical uncoupling induced by ischemia. Circ Res 87(8):656-662

55. Sabatasso S, Mangin P, Fracasso T, Moretti M, Docquier M, Djonov V (2016) Early markers for myocardial ischemia and sudden cardiac death. Int J Legal Med 130(5):1265-1280. https://doi. org/10.1007/s00414-016-1401-9

56. Turillazzi E, Pomara C, Bello S, Neri M, Riezzo I, Fineschi V (2015) The meaning of different forms of structural myocardial injury, immune response and timing of infarct necrosis and cardiac repair. Curr Vasc Pharmacol 13(1):6-19. https://doi.org/10.2174/ 15701611113119990008

57. Aljakna A, Lauer E, Lenglet S, Grabherr S, Fracasso T, Augsburger M, Sabatasso S, Thomas A (2018) Multiplex quantitative imaging of human myocardial infarction by mass spectrometry-immunohistochemistry. Int J Legal Med 132(6):1675-1684. https://doi.org/10. 1007/s00414-018-1813-9

58. Basso C, Rizzo S, Thiene G (2010) The metamorphosis of myocardial infarction following coronary recanalization. Cardiovasc Pathol 19(1):22-28. https://doi.org/10.1016/j.carpath.2009.06.010

59. Dettmeyer RB (2018) Coronary sclerosis, myocardial infarction, myocarditis, cardiomyopathy, coronary anomalies. In Forensic Histopathology Springer International Berlin Heidelberg

60. Grundeken MJ, Li X, Kurpershoek CE, Kramer MC, Vink A, Piek JJ, Tijssen JGP, Koch KT, Wykrzykowska JJ, de Winter RJ, van der 
Wal AC (2015) Distal embolization of hydrophilic-coating material from coronary guidewires after percutaneous coronary interventions. Circ Cardiovasc Interv 8(2):e001816. https://doi.org/10. 1161/CIRCINTERVENTIONS.114.001816

61. Hoffman JI, Buckberg GD (2014) The myocardial oxygen supply: demand index revisited. J Am Heart Assoc 3(1):e000285. https:// doi.org/10.1161/JAHA.113.000285

62. Shimizu I, Minamino T (2016) Physiological and pathological cardiac hypertrophy. J Mol Cell Cardiol 97:245-262. https://doi.org/ 10.1016/j.yjmcc.2016.06.001

63. van den Heuvel AFM, van Veldhuisen DJ, van der Wall EE, Blanksma PK, Siebelink HMJ, Vaalburg WM, van Gilst WH, Crijns HJGM (2000) Regional myocardial blood flow reserve impairment and metabolic changes suggesting myocardial ischemia in patients with idiopathic dilated cardiomyopathy. J Am Coll Cardiol 35(1):19-28. https://doi.org/10.1016/S0735-1097(99)00499-4

64. Ghadri JR, Wittstein IS, Prasad A, Sharkey S, Dote K, Akashi YJ, Cammann VL, Crea F, Galiuto L, Desmet W, Yoshida T, Manfredini R, Eitel I, Kosuge M, Nef HM, Deshmukh A, Lerman A, Bossone E, Citro R, Ueyama T, Corrado D, Kurisu S, Ruschitzka F, Winchester D, Lyon AR, Omerovic E, Bax JJ, Meimoun P, Tarantini G, Rihal C, Y.-Hassan S, Migliore F, Horowitz JD, Shimokawa H, Lüscher TF, Templin C (2018) International expert consensus document on Takotsubo syndrome (part I): clinical characteristics, diagnostic criteria, and pathophysiology. Eur Heart $\mathrm{J}$ 39(22):2032-2046. https://doi.org/10.1093/eurheartj/ehy076

65. Templin C, Hanggi J, Klein C et al (2019) Altered limbic and autonomic processing supports brain-heart axis in Takotsubo syndrome. Eur Heart J 40(15):1183-1187. https://doi.org/10.1093/ eurheartj/ehz068

66. Loscalzo J, Roy N, Shah RV, Tsai JN, Cahalane AM, Steiner J, Stone JR (2018) Case 8-2018: a 55-year-old woman with shock and labile blood pressure. N Engl J Med 378(11):1043-1053. https://doi.org/10.1056/NEJMcpc1712225

67. Armiger LC, Ian Smeeton WM (1986) Contraction-band necrosis: patterns of distribution in the myocardium and their diagnostic usefulness in sudden cardiac death. Pathology 18(3):289-295. https:// doi.org/10.3109/00313028609059479

68. Bunai Y, Akaza K, Tsujinaka M et al (2003) Myocardial damage by resuscitation methods. Leg Med (Tokyo) 5(Suppl 1):S302-S306. https://doi.org/10.1016/S1344-6223(02)00156-6

69. Stechovsky C, Hajek P, Cipro S, Veselka J (2015) Risk of myocardial contusion in cardiac arrest patients resuscitated with mechanical chest compression device. Int J Cardiol 182:50-51. https://doi. org/10.1016/j.ijcard.2014.12.059

70. Roberts ISD, Traill ZC (2014) Minimally invasive autopsy employing post-mortem $\mathrm{CT}$ and targeted coronary angiography: evaluation of its application to a routine coronial service. Histopathology 64(2):211-217. https://doi.org/10.1111/his.12271

71. Grabherr S, Heinemann A, Vogel H, Rutty G, Morgan B, Woźniak K, Dedouit F, Fischer F, Lochner S, Wittig H, Guglielmi G, Eplinius F, Michaud K, Palmiere C, Chevallier C, Mangin P, Grimm JM (2018) Postmortem CT angiography compared with autopsy: a forensic multicenter study. Radiology 288(1):270-276. https://doi. org/10.1148/radiol.2018170559

72. Michaud K, Grabherr S, Jackowski C, Bollmann MD, Doenz F, Mangin P (2014) Postmortem imaging of sudden cardiac death. Int J Legal Med 128(1):127-137. https://doi.org/10.1007/s00414013-0819-6

73. Morgan B, Biggs MJ, Barber J, Raj V, Amoroso J, Hollingbury FE, Robinson C, Rutty GN (2013) Accuracy of targeted post-mortem computed tomography coronary angiography compared to assessment of serial histological sections. Int J Legal Med 127(4):809817. https://doi.org/10.1007/s00414-012-0790-7

74. Michaud K, Grabherr S, Faouzi M, Grimm J, Doenz F, Mangin P (2015) Pathomorphological and CT-angiographical characteristics of coronary atherosclerotic plaques in cases of sudden cardiac death. Int J Legal Med 129(5):1067-1077. https://doi.org/10. 1007/s00414-015-1191-5

75. Fernández-Jiménez R, Barreiro-Pérez M, Martin-García A, Sánchez-González J, Agüero J, Galán-Arriola C, García-Prieto J, Díaz-Pelaez E, Vara P, Martinez I, Zamarro I, Garde B, Sanz J, Fuster V, Sánchez PL, Ibanez B (2017) Dynamic edematous response of the human heart to myocardial infarction: implications for assessing myocardial area at risk and salvage. Circulation $136(14): 1288-1300$. https://doi.org/10.1161/ CIRCULATIONAHA.116.025582

76. Sabatasso S, Vanhaebost J, Doenz F et al (2018) Visualization of myocardial infarction in postmortem multiphase computed tomography Angiography: a feasibility study. Am J Forensic Med Pathol. https://doi.org/10.1097/PAF.0000000000000372

77. Jackowski C, Christe A, Sonnenschein M, Aghayev E, Thali MJ (2006) Postmortem unenhanced magnetic resonance imaging of myocardial infarction in correlation to histological infarction age characterization. Eur Heart J 27(20):2459-2467. https://doi.org/ 10.1093/eurheartj/ehl255

78. Persson A, Baeckmann J, Berge J, Jackowski C, Warntjes M, Zech W-D (2018) Temperature-corrected postmortem 3-T MR quantification of histopathological early acute and chronic myocardial infarction: a feasibility study. Int J Legal Med 132(2):541-549. https://doi.org/10.1007/s00414-017-1614-6

79. Roffi M, Patrono C, Collet JP, Mueller C, Valgimigli M, Andreotti F, Bax JJ, Borger MA, Brotons C, Chew DP, Gencer B, Hasenfuss G, Kjeldsen K, Lancellotti P, Landmesser U, Mehilli J, Mukherjee D, Storey RF, Windecker S (2016) 2015 ESC guidelines for the management of acute coronary syndromes in patients presenting without persistent ST-segment elevation: task force for the management of acute coronary syndromes in patients presenting without persistent ST-segment elevation of the European Society of Cardiology (ESC). Eur Heart J 37(3):267-315. https://doi.org/10. 1093/eurheartj/ehv320

80. Thygesen K, Mair J, Giannitsis E, Mueller C, Lindahl B, Blankenberg S, Huber K, Plebani M, Biasucci LM, Tubaro M, Collinson P, Venge P, Hasin Y, Galvani M, Koenig W, Hamm C, Alpert JS, Katus H, Jaffe AS, the Study Group on Biomarkers in Cardiology of the ESC Working Group on Acute Cardiac Care (2012) How to use high-sensitivity cardiac troponins in acute cardiac care. Eur Heart J 33(18):2252-2257. https://doi.org/10.1093/ eurheartj/ehs 154

81. González-Herrera L, Valenzuela A, Ramos V, Blázquez A, Villanueva E (2016) Cardiac troponin T determination by a highly sensitive assay in postmortem serum and pericardial fluid. Forensic Sci Med Pathol 12(2):181-188. https://doi.org/10.1007/s12024016-9749-1

82. Beausire T, Faouzi M, Palmiere C, Fracasso T, Michaud K (2018) High-sensitive cardiac troponin hs-TnT levels in sudden deaths related to atherosclerotic coronary artery disease. Forensic Sci Int 289:238-243. https://doi.org/10.1016/j.forsciint.2018.05.051

Publisher's note Springer Nature remains neutral with regard to jurisdictional claims in published maps and institutional affiliations. 